\title{
Expressiveness and Sedation in Opera Music: Mathematical Perspectives
}

\author{
(iD) Yang Chao \\ Guangxi Arts University, Guangxi, China. Midwest University, Wentzville, USA \\ 387205585@qq.com
}

\begin{abstract}
The study purpose is to consider the influence of expressive and sedative opera works on the respondents' mathematical abilities. The respondents were tested in order to identify the above characteristics. Two samples were obtained that contain information indirectly indicating a change in mathematical abilities of respondents listening to expressive and sedative opera works. There is a correlation between listening to music and an increase in the respondents' mathematical abilities. The correlations between listening to sedative and expressive music and the respondents' mathematical ability are different. Sedative music has a calming effect while expressive music cheers up the respondents.
\end{abstract}

Keywords: Cognitive abilities. Expressive music. Mathematics. Opera. Sedative music.

Resumo: O objetivo do estudo é considerar a influência de obras de ópera expressivas e sedativas nas habilidades matemáticas dos entrevistados. Os respondentes foram testados a fim de identificar as características acima. Foram obtidas duas amostras que contêm informações que indicam indiretamente uma mudança nas habilidades matemáticas dos entrevistados ao ouvir obras de ópera expressivas e sedativas. Existe uma correlação entre ouvir música e um aumento nas habilidades matemáticas dos entrevistados. As correlações entre ouvir música sedativa e expressiva e a habilidade matemática dos entrevistados são diferentes. A música sedativa tem um efeito calmante, enquanto a música expressiva anima os entrevistados.

Palavras-chave: Habilidades cognitivas. Música expressiva. Matemática. Ópera. Música sedativa.

Submetido em: 27 de maio de 2021

Aceito em: 31 de julho de 2021 
Expressiveness and Sedation in Opera Music: Mathematical Perspectives Yang Chao

\section{Introduction}

The interdisciplinary field of music and mathematics has been studied for a long time and has been rapidly developing over the past decade. Research at the intersection of music and mathematics often covers the areas of pedagogy (AN et al., 2016; HAMILTON et al., 2018) and linguistics (BERGEE and WEINGARTEN, 2021; VAN DE CAVEY and HARTSUIKER, 2016).

There are many studies on the impact of different types of music on human mathematical and cognitive abilities (HOLMES and HALLAM, 2017; SCHELLENBERG, 2005; VILADOT et al., 2017). In particular, a pilot study (HAMILTON et al., 2018) considers whether knowledge in such fundamental mathematics topics as fractions, equations, multiplication, and division can affect the students' sense of rhythm. The results obtained showed that the perfomance of students improved after the post-test. This study also raises the question of the concept of human musical abilities. In addition, there was a similar study (AN and TILLMAN, 2015) based on a preand post-test experiment involving 56 primary school students. Within the framework of the present paper, it was revealed that the introduction of interdisciplinary music and mathematics classes has significantly improved the mathematical abilities of children. In the course of the study (LAATO et al., 2019), the introduction of music classes into the school curriculum of educational institutions in Finland was substantiated. As part of an experiment conducted in high school, it was observed that composition lessons had significantly improved the mathematical abilities of the respondents, in particular, the skills of basic calculation. According to the study, good knowledge of music theory and teacher competence are important for conducting composition lessons. It should be noted that composing is quite difficult to assess objectively. However, upto-date computer software developed in the study (LAATO et al., 2019) can solve the above problems quite successfully. The work of MCDONEL (2015) found a significant correlation between the musical ability of preschool children (namely, the sense of rhythm) 
Expressiveness and Sedation in Opera Music: Mathematical Perspectives Yang Chao

and their mathematical abilities. However, it should be noted that despite the long-term experiment lasting 12 weeks, the respondent sample was rather small - only ten children.

The study of fractions is one of the challenges to children when learning mathematics (BAILEY et al., 2015; LORTIE-FORGUES et al., 2015). The study of LOVEMORE et al. (2021) considers the effect of the introduction of music classes on the mastery of fractions by secondary school children in South Africa. Within the framework of the research, the interdependent study of music and mathematics for the development of mathematical abilities of children was proposed. The work AZARYAHU et al. (2019) also investigated the impact of the introduction of music classes on the ability to learn fractions. All respondents who participated in the 12-week experiment were divided into three groups: the first group was engaged in musical activities with an emphasis on rhythm and melody activities; the second group was involved in rhythmic activities; in the third group, there was no musical interference. The main methodology of the experiment based on the pre and post test was teaching musical notation and rhythmic lessons conducted by tapping melody the respondents heard. Despite the good indicators of the mathematical ability to solve fraction problems in both music groups, a significant positive result was noticed only in the first group.

The study of SCHELLENBERG (2005) examines the impact of music on human cognitive abilities (in particular, memory, language and visual motor skills). The work analyzes mathematical abilities before and after listening to music (the so-called Mozart effect). It is important to note that the study did not find any correlation between listening to music and musical ability improvement, but there was a beneficial effect of music on language skills. However, the work of ANGEL et al. (2010) described completely different results - listening to music by Mozart really improves the cognitive abilities of a person. There is more information on the effect of music on cognitive (in particular, mathematical abilities of a person) in the studies of HAUSER and WATUMULL (2017), ROGERS (2004), SAMSUDIN et al. (2019). 
Expressiveness and Sedation in Opera Music: Mathematical Perspectives Yang Chao

Also, it should be noted that music therapy can greatly help sick people (GARCÍA-CASARES et al., 2018; KRABS et al., 2015; PALISSON et al., 2015). For example, the researchers (SCHIAVIO and ALTENMÜLLER, 2015) observed that music therapy improves the well-being of people with Parkinson's disease. In particular, it has been noted that this type of therapy has a positive effect on coordination and motor abilities, as well as stabilizes psychological state and improves social skills. However, contrary to conventional wisdom, the research (KENNAWAY, 2015) found that music therapy can cause serious physical and mental disorders. Considering the effect of music on people in different eras, the author noted that according to some people (in particular, the nineteenth and twentieth centuries were considered), music can "brainwash" or make young women feel faint. However, the authors of this work believe that these are prejudices caused by the inadequate competence of people of that time in medicine. It is likely that nineteenth-century women fainted from too tight corsets, and twentieth-century brainwashing was the result of the fear of the Cold War.

Within the framework of the present paper, the influence of sedative and expressive music on the mathematical abilities of a person was considered. The purpose of the study is to reveal and confirm a positive correlation between listening to music of a different nature and better mathematics performance. In addition, the data that will provide an abstract and subjective definition of "expressiveness" were collected through the survey. The objective of the study was to collect and analyze data that indicate the effect of different types of music on the mathematical ability of a person. A three-week experiment conducted based on the pre- and posttest method showed that both expressive and sedative music have a positive effect on the mathematical ability of the respondents. However, sedative music has a greater impact on the respondents' performance in mathematics. 


\section{Research Methodology}

\section{Preliminary Selection Methodology}

Within the framework of the study, 639 students from various universities located in China were selected. Initially, 832 students agreed to participate in the experiment; but the main selection criterion was poor knowledge of mathematics. Thus, based on the pre-test (the respondents were given a form containing test tasks in school mathematics), some of the participants who were good enough at mathematics were refused to participate. The selection criterion is due to the fact that a change in student performance should be checked by giving more complex mathematical problems. In addition, all respondents were previously explained the methods of solving problems.

All respondents selected were divided into three groups. Thus, there were 213 people in each group.

It should be noted that factors such as gender, social or financial status were not taken into account.

\section{Research Methodology}

The experiment conducted within the framework of the study involved three-week listening to opera music of a different nature during sleep and during the day (the respondents were required to listen to opera music instead of the music they usually prefer). The data collection methodology is based on the interviews of students (three-day testing under the supervision of 87 teachers) on various elementary mathematics topics (multiplication, division, and addition of simple and decimal fractions; solving linear equations, power problems, Pythagorean equations to find different sides of right-angled triangles, as well as solving quadratic equations based on Vieta's theorem). The respondents were also required to define "expressiveness". In this case, at the end of the experiment, the respondents verbally described the feelings expressive music 
Expressiveness and Sedation in Opera Music: Mathematical Perspectives Yang Chao

provoked in them. It should be noted that "sedative music" did not require definition as almost all respondents defined it as "calm".

\section{Statistical Research Methods}

Within the framework of the research, a dataset grouped into three paired samples was obtained. Each pair was the pre- and post-test result of the three study groups (one control group and two experimental groups).

The data in the samples reflected the number of respondents who answered the questions.

The data obtained were analyzed based on the two-sample t-test for independent variables. However, a prerequisite tor the application of this statistical method is the sample size of more than 8 and conformity with the student's normal distribution. The first condition is true (12>8), the second one is checked through the Shapiro-Wilk criterion, which is found according to the formula:

where is the sample variance, are sample values, and are table constants.

In this case, the normality of the sample is confirmed unless the empirical values exceed the critical value. The critical value of the Shapiro-Wilk test depends on the size of the samples and is calculated by the following formula:

where $\mathrm{n}$ is the sample size.

As noted above, the Student's t-test is the main method of testing the hypothesis for the correlation between listening to sedative or expressive opera music and the improvement in the mathematical ability of the respondents. The Student's t-test is found by the formula 
Expressiveness and Sedation in Opera Music: Mathematical Perspectives Yang Chao

where is the arithmetic mean of the sample, and $s$ is the variance of the sample.

The hypothesis under study is confirmed if the t-test values exceed the table value that is 2.2 .

The analysis was carried out taking into account the reliability coefficient of 0.05 used for any experimental data.

\section{Ethical Issues}

The respondents were not asked to mention their names and universities, and teachers from other universities were invited. It was also previously checked that the respondents do notstudy attechnical faculties. Both written and verbal consent for participation in research were received. The research was approved by the Ethics Review Committee of Guangxi Arts University (protocol number IC3451AJ2_RES).

\section{Research Limitations}

However, it should be noted that there are a number of factors that can slightly distort the results obtained. These include a relatively small number of questions in the questionnaire. Despite the fact that the number of questions allows the application of the Student's t-test $(12>8)$, the larger the amount of data in the samples, the more accurate the results are. In addition, a more careful selection of respondents based on different factors of influence can be performed. Thus, the study not only confirms the correlation, but also substantiates the need for further research in the area.

\section{Results and Discussion}

Within the framework of the study, two types of oral testing of respondents were carried out. The first survey involved mental 
Expressiveness and Sedation in Opera Music: Mathematical Perspectives Yang Chao

calculation to solve basic mathematics tasks (Table 1 and Table 2). In the second survey, the respondents were asked to define "expressiveness". The results are given below.

\section{Survey 1.}

In the course of the study based on the pre- and post-test method, three paired samples were obtained.

Table 1 shows the results that indirectly indicate a change in the mathematical abilities of the control group respondents. Column 1 contains question numbers ("Note"). Column 3 and 4 show test results one day before the experiment and three weeks after the experiment, respectively.

Table 1 - Control group results.

\begin{tabular}{|lll|}
\hline CONTROL GROUP \\
\hline TASK NO. & PRE-TEST & POST-TEST \\
\hline 1 & 389 & 392 \\
\hline 2 & 385 & 386 \\
\hline 3 & 379 & 380 \\
\hline 4 & 382 & 382 \\
\hline 5 & 378 & 377 \\
\hline 6 & 385 & 388 \\
\hline 7 & 386 & 386 \\
\hline 8 & 370 & 372 \\
\hline 9 & 379 & 382 \\
\hline 10 & 383 & 388 \\
\hline 11 & 388 & 386 \\
\hline 12 & 385 & 380 \\
\hline
\end{tabular}

The highest pretest sample value is 389 for question 1 and the lowest - 370 for question 8. For the second sample, the results are a bit better. However, further analysis based on the Student's t-test showed that these differences are not significant. For the second sample, the highest value is 372, and the lowest - 392 for the same questions.

Table 2 and 3 present the results of the experimental groups that listened to sedative (experimental group 1) and expressive music (experimental group 2). Similarly to Table 1, the first, second, and third columns correspond to question numbers and pre- and post-test results, respectively. 
Expressiveness and Sedation in Opera Music: Mathematical Perspectives Yang Chao

Table 2 - Results of the experimental group listening to sedative opera music.

\begin{tabular}{|lll|}
\hline \multicolumn{3}{|c|}{ EXPERIMENTAL GROUP 1} \\
\hline \multicolumn{3}{|c|}{ PRE- } \\
TASK NO. & TEST & POST-TEST \\
\hline 1 & 390 & 748 \\
\hline 2 & 386 & 746 \\
\hline 3 & 388 & 742 \\
\hline 4 & 382 & 743 \\
\hline 5 & 382 & 714 \\
\hline 6 & 383 & 719 \\
\hline 7 & 385 & 710 \\
\hline 8 & 380 & 709 \\
\hline 9 & 383 & 710 \\
\hline 10 & 385 & 711 \\
\hline 11 & 387 & 711 \\
\hline 12 & 388 & 713 \\
\hline
\end{tabular}

In this case, for experimental group 1, the highest and lowest indicators in the first column are 390 and 380, and in the second one - 709 and 748. As for the post- and pre-test results of the control group, the respondents found question 1 to be the easiest while question 2 caused the greatest difficulty.

Table 3 - Results of the experimental group listening to expressive opera music.

\begin{tabular}{|lll|}
\hline EXPERIMENTAL GROUP 2 & \\
\hline TASK NO. & PRE-TEST & POST-TEST \\
\hline 1 & 391 & 582 \\
\hline 2 & 382 & 563 \\
\hline 3 & 383 & 564 \\
\hline 4 & 385 & 566 \\
\hline 5 & 384 & 567 \\
\hline 6 & 386 & 564 \\
\hline 7 & 383 & 569 \\
\hline 8 & 381 & 561 \\
\hline 9 & 388 & 568 \\
\hline 10 & 386 & 562 \\
\hline 11 & 387 & 565 \\
\hline 12 & 385 & 568 \\
\hline
\end{tabular}

For experimental group 2, as well as for the other groups, the highest and lowest values corresponded to the same questions. The lowest and highest pre-test and post-test values were 381 and 391, and 561 and 582, respectively. 
Expressiveness and Sedation in Opera Music: Mathematical Perspectives Yang Chao

Table 4 shows the results of the analysis of the samples obtained in the context of their compliance with the law of normal distribution. It was checked based on the Shapiro-Wilk test. In line 3 , number 1 and number 2 correspond to the pre- and post-test samples for the control group, and number 3, 4, 5 and 6 correspond to the pre- and post-test values for experimental group 1 ( 3 and 4 ) and experimental group 2 (5 and 6).

Table 4 - Results of the analysis of the samples based on the Shapiro-Wilk test.

\begin{tabular}{|l|l|l|l|l|l|l|}
\hline \multirow{2}{*}{ VALUES } & \multicolumn{9}{l|}{ SHAPIRO-WILK CRITERION } \\
\cline { 2 - 8 } & 1 & 2 & 3 & 4 & 5 & 6 \\
\hline $\mathrm{X}>$ & 382.4167 & 383.25 & 384.9167 & 723 & 385.0833 & 566.5833 \\
\hline $\mathrm{S}^{2}$ & 5.04000 & 5.27770 & 2.87110 & 7.22072 & 2.66010 & 3.05850 \\
\hline $\mathrm{W}$ & 0.789682 & 0.65908 & 0.801821 & 0.79803 & 0.812467 & 0.818576 \\
\hline
\end{tabular}

Line 1 and line 2 show the arithmetic mean of the sample and the variance, respectively.

As can be seen, for the control group, the mean pre- and posttest values of 382.4167 and 383.25 are rather close, while for the experimental groups, the differences are quite large - 384.9167 and 723 for the first group, and 385.0833 and 566.5833 for the second one. Line 3 shows the results of the Shapiro-Wilk test. Thus, due to the fact that all values obtained do not exceed the critical one (0.850908), the law of normal distribution is fulfilled.

Table 5 shows the results of the analysis of the paired samples based on the Student's t-test. Column 1, 2, and 3 show the results of comparing paired samples for the control and experimental samples (first and second). Line 1 shows the root-mean-square variance for the two pairs of samples, line 2 - the empirical Student's t-test. 
Expressiveness and Sedation in Opera Music: Mathematical Perspectives Yang Chao

Table 5 - Results of the analysis of the samples based on the Student's t-test.

\begin{tabular}{|l|lll|}
\hline \multirow{2}{*}{ VALUES } & STUDENT'S T-TEST & & \\
& & & \\
& CONTROL GROUP & EXPERIMENTAL GROUP 1 & $\begin{array}{l}\text { EXPERIMENTAL GROUP } \\
2\end{array}$ \\
\hline $\mathrm{S}^{2}$ & 0.859808333 & 0.84099 & 0.47655 \\
\hline $\mathrm{T}$ & 0.256347069 & 4.743044421 & 6.300820101 \\
\hline
\end{tabular}

As the t-test value of the control group does not exceed the table value, the hypothesis for the correlation is rejected. The Student's t-test values of the experimental groups exceed the table one; therefore, the correlation is confirmed. Thus, there is a correlation between listening to opera music and improvement of the mathematical abilities of the respondents. However, in the context of sedative music, the correlation is stronger.

\section{Survey 2}

In the second survey, respondents were asked to define "expressiveness". The overwhelming majority of the respondents characterized the term exclusively with epithets. Within the framework of the study, the most common epithets used were "motivating", "shivering", "exciting" and "uplifting".

Next, more detailed characteristics are given.

1. "It's quite difficult to describe ... This kind of music definitely cheers me up. I would say that it encourages action."

2. "I think this kind of music can be described as exciting. Perhaps, my basic feeling resembles anxiety."

3. "This music is rather unusual for me. It's not that it makes me scared, but it's a bit frightening for me. It's hard to describe it verbally."

4. "In general, I love opera music, but I don't listen to it all the time. She helps me focus and cheers me up."

5. "Obviously, not everyone enjoys this kind of music. It has a special character and is very aesthetic."

6. "This kind of music makes me think. This is a kind of intellectual load." 
Expressiveness and Sedation in Opera Music: Mathematical Perspectives Yang Chao

7. "Despite the fact that it is clearly not calm, I would describe opera music as meditative because while listening to it, you disengage yourself from the outside world."

The impact of different types of music on the cognitive (in particular, mathematical) abilities of a person is well studied. Thus, the work of GAN et al. (2015) considers the effect of sedative music on the level of mathematical anxiety among the respondents. As part of the study involving 100 bachelors of the Faculty of Psychology, an experiment was conducted in three groups: the first two groups listened to sedative and stimulative music, respectively, and the third one did not listen to music. The research based on the pre- and post-test study revealed that both sedative and stimulative music reduced mathematical anxiety (in particular, the results showed a decrease in systolic blood pressure). However, it was also observed that stimulative music is less effective in this case. If expressiveness is interpreted as stimulative music (the respondents characterized expressive music with similar epithets in our study), it can be argued that the results obtained in this study are similar to our results. In addition, it should be noted that within the framework of our experiment, a similar research methodology based on pre- and post-tests followed by further analysis with the use of the Student's t-test was applied. The work of TISDELL (2019) investigates the impact of integrating songs on maths learning. As part of the study, the researcher created the song called "e is magic number" and integrated it into his classes with students. The study showed that the introduction of musical works of this type can also have a positive effect on the musical abilities of the respondents and help them better memorize the material received in the classroom. However, a meta-analysis (SALA and GOBET, 2020) described opposite results. Within the framework of the study, various methods of assessing the effectiveness of musical activity (verbal, non-verbal, speed-related, etc.) were implemented; each of them showed poor effectiveness or no results. Despite testing of respondents of different age and at different time of the experiment, there was no significant correlation between musical 
Expressiveness and Sedation in Opera Music: Mathematical Perspectives Yang Chao

activity and an improvement in the mathematical abilities of the respondents. Later, the same authors came to a similar conclusion (SALA and GOBET, 2017). The study of FANCOURT and STEPTOE (2018) involving 3445 respondents found that going to the theater, as well as attending concerts and operas, exhibitions, museums and galleries, have a beneficial effect on the cognitive abilities of adults aged 25 and older for the next 10 years. Regardless of the demographic status of the respondents, their health, and social status, this correlation remains. Based on the results of the study of BENZ et al. (2016), it was noted that musical activity as a type of cognitive training can also improve cognitive abilities of a person.

\section{Conclusions and Future Work}

Within the framework of the study, a three-week experiment involving passive listening to sedative and expressive opera music was conducted. The respondents (639 students from various universities in China) listened to opera music while sleeping. The respondents were required to neglect their musical preferences and listen to sedative or expressive pieces of music instead.

In the course of the experiment, a correlation between listening to sedative and expressive opera music and an improvement in the mathematical abilities of the respondents was observed. The samples analyzed based on the two-sample Student's t-test for independent variables showed that the pre-test results were much worse compared to the post-test results in the the experimental groups while the results of the control group almost did not change. However, sedative music has a greater effect on the improvement of cognitive abilities (the pre-test based on the results of the respondents showed an average value of 384.9167 while the post-test - 723). Despite this, the expressiveness of opera music should not be underestimated as the results of the second group respondents also improved significantly (the pre-test mean value is 385.0833 , the post-test value -563566.5833 ). In addition, the results 
Expressiveness and Sedation in Opera Music: Mathematical Perspectives Yang Chao

of the interview of respondents provided quite comprehensive and similar characteristics of "expressiveness". Thus, many respondents described this type of music as "motivating", "shivering", "exciting" and "uplifting". However, some respondents gave not quite correct answers. For example, some respondents called expressive opera music loud and "screaming". Some respondents also noted that this kind of music interferes with concentration.

The results obtained can be used to integrate interdisciplinary music and mathematics classes. Also, there is a problem of underestimating music as a subject of the school curriculum. However, as our results have shown, music can affect the assimilation of exact sciences. It is planned to conduct a more thorough selection of respondents to participate in further research. In addition, to obtain a more reliable result, it is necessary to increase the number of test items in the questionnaire. The results obtained can also serve as an argument for the research on the correlation between mathematical ability and listening to other types of music.

\section{References}

AN, Song A.; TILLMAN, Daniel A. Music activities as a meaningful context for teaching elementary students mathematics: A quasi-experiment time series design with random assigned control group. European Journal of Science and Mathematics Education, Bastas, v. 3, n. 1, p. 45-60, 2015.

AN, Song A.; ZHANG, Meilan; TILLMAN, Daniel A.; LESSER, Lawrence M.; SIEMSSEN, Annette; TINAJERO, Josefina V. Learning to teach musicthemed mathematics: An examination of preservice teachers' beliefs about developing and implementing interdisciplinary mathematics pedagogy. Mathematics Teacher Education and Development, v. 18, n. 1, p. 20-36, 2016.

ANGEL, Leslie A.; POLZELLA, Donald J.; ELVERS, Greg C. Background music and cognitive performance. Perceptual and Motor Skills, New York, NY, v. 110, n. 3C, p. 1059-1064, 2010. 
Expressiveness and Sedation in Opera Music: Mathematical Perspectives Yang Chao

AZARYAHU, Libby; COUREY, Susan Joan; ELKOSHI, Rivka; ADIJAPHA, Esther. 'MusiMath' and 'Academic Music'- Two music-based intervention programs for fractions learning in fourth grade students. Developmental Science, Oxford, v. 23, n. 4, p. e12874, 2019.

BAILEY, Drew H.; ZHOU, Xinlin; ZHANG, Yiyun; CUI, Jiaxin; FUCHS, Lynn S.; JORDAN, Nancy C.; GERSTEN, Russel; SIEGLER, Robert S. Development of fraction concepts and procedures in U.S. and Chinese children. Journal of Experimental Child Psychology, Cambridge, MA, v. 129, p. 68-83, 2015.

BENZ, Sarah; SELLARO, Roberta; HOMMEL, Bernhard; COLZATO, Lorenza S. Music makes the world go round: The impact of musical training on non-musical cognitive functions-A review. Frontiers in Psychology, Lausanne, v. 6, p. 2023, 2016.

BERGEE, Martin J.; WEINGARTEN, Kevin M. Multilevel models of the relationship between music achievement and reading and math achievement. Journal of Research in Music Education, New York, NY, v. 68, n. 4 , p. 398-418, 2021.

FANCOURT, Daisy; STEPTOE, Andrew. Cultural engagement predicts changes in cognitive function in older adults over a 10 year period: findings from the English longitudinal study of ageing. Scientific Reports, London, v. 8, n. 1, p. 10226, 2018.

GAN, Samuel Ken-En; LIM, Keane Ming-Jie; HAW, Yu-Xuan. The relaxation effects of stimulative and sedative music on mathematics anxiety: A perception to physiology model. Psychology of Music, London, v. 44, n. 4, p. 730-741, 2015.

GARCÍA-CASARES, Natalia; MARTÍN-COLOM, Julia Eva; GARCÍA-ARNÉS, Juan Antonio. Music therapy in Parkinson's disease. Journal of the American Medical Directors Association, New York, NY, v. 19, n. 12, p. 1054-1062, 2018.

HAMILTON, Tara Julia; DOAI, Julieanne; MILNE, Andrew; SAISANAS, Vicky; CALILHANNA, Andrea; HILTON, Courtney; GOLDWATER, Micah; $\mathrm{COHN}$, Richard. Teaching mathematics with music: A pilot study. In: 2018 IEEE International Conference on Teaching, Assessment, and Learning for Engineering (TALE). Piscataway: IEEE, 2018. p. 927-931. 
Expressiveness and Sedation in Opera Music: Mathematical Perspectives Yang Chao

HAUSER, Marc D.; WATUMULL, Jeffrey. The universal generative faculty: The source of our expressive power in language, mathematics, morality, and music. Journal of Neurolinguistics, Edinburgh, v. 43, p. 78-94, 2017.

HOLMES, Sylwia; HALLAM, Susan. The impact of participation in music on learning mathematics. London Review of Education, London, v. 15, n. 3, p. 425-438, 2017.

KENNAWAY, James. Historical perspectives on music as a cause of disease. Progress in Brain Research, Amsterdam, v. 216, p. 127-145, 2015.

KRABS, Roland Uwe; ENK, Ronny; TEICH, Niels; KOELSCH, Stefan. Autonomic effects of music in health and Crohn's disease: The impact of isochronicity, emotional valence, and tempo. PLOS ONE, San Francisco, CA, v. 10, n. 5, p. e0126224, 2015.

LAATO, Samuli; LAINE, Teemu; SUTINEN, Erkki. Affordances of music composing software for learning mathematics at primary schools. Research in Learning Technology, Chesterton, v. 27, p. 2259, 2019. LORTIE-FORGUES, Hugues; TIAN, Jing; SIEGLER, Robert S. Why is learning fraction and decimal arithmetic so difficult? Developmental Review, Maryland Heights, MO, v. 38, p. 201-221, 2015.

LOVEMORE, Tarryn S.; ROBERTSON, Sally-Ann; GRAVEN, Mellony. Enriching the teaching of fractions through integrating mathematics and music. South African Journal of Childhood Education, Cape Town, v. 11, n. 1, p. 899, 2021.

MCDONEL, Jennifer S. Exploring learning connections between music and mathematics in early childhood. Bulletin of the Council for Research in Music Education, Champaign, IL, v. 203, p. 45-62, 2015. PALISSON, Juliette; ROUSSEL-BACLET, Caroline; MAILLET, Didier; BELIN, Catherine; ANKRI, Joël; NARME, Pauline. Music enhances verbal episodic memory in Alzheimer's disease. Journal of Clinical and Experimental Neuropsychology, London, v. 37, n. 5, p. 503-517, 2015. 
Expressiveness and Sedation in Opera Music: Mathematical Perspectives Yang Chao

ROGERS, George L. Interdisciplinary lessons in musical acoustics: The science-math-music connection. Music Educators Journal, London, v. 91, n. 1, p. 25-30, 2004.

SALA, Giovanni; GOBET, Fernand. When the music's over. Does music skill transfer to children's and young adolescents' cognitive and academic skills? A meta-analysis Author links open overlay panel. Educational Research Review, Oxford, v. 20, p. 55-67, 2017. SALA, Giovanni; GOBET, Fernand. Cognitive and academic benefits of music training with children: A multilevel meta-analysis. Memory \& Cognition, New York, NY, v. 48, n. 8, p. 1429-1441, 2020.

SAMSUDIN, Mohamad Azam; BAKAR, Kamariah Abu; NOOR, Noorhayati Mohd. The benefits of music and movement in early mathematics. Creative Education, Wuhan, v. 10, n. 12, p. 3071-3081, 2019. SCHELLENBERG, E. Glenn. Music and cognitive abilities. Current Directions in Psychological Science, New York, NY, v. 14, n. 6, p. 317320, 2005.

SCHIAVIO, Andrea; ALTENMÜLLER, Eckart. Exploring music-based rehabilitation for Parkinsonism through embodied cognitive science. Frontiers in Neurology, Lausanne, v. 6, p. 217, 2015.

TISDELL, Christopher C. An arts-integrated approach to learning mathematics through music: A case study of the song 'e is a magic number'. International Journal of Innovation in Science and Mathematics Education, Sydney, v. 27, n. 7, p. 46-61, 2019. VAN DE CAVEY, Joris; HARTSUIKER, Robert J. Is there a domain-general cognitive structuring system? Evidence from structural priming across music, math, action descriptions, and language. Cognition, Amsterdam, v. 146, p. 172-184, 2016.

VILADOT, Laila; HILTON, Caroline; CASALS, Albert; SAUNDERS, Jo; CARRILLO, Carmen; HENLEY, Jennie; GONZÁLEZ-MARTÍN, Cristina; PRAT, Monserrat; WELCH; Graham. The integration of music and mathematics education in Catalonia and England: perspectives on theory and practice. Music Education Research, London, v. 20, n. 1, p. 71-82, 2017. 
Expressiveness and Sedation in Opera Music: Mathematical Perspectives Yang Chao

\section{Appendix 1}

1. Add and reduce the fraction

2. $=$ Multiply and reduce the fraction

3. $x+134.5-2.4=164.2$

4. Find $x$

5. Find $x$ based on Vieta's formula

6. Find the length of the hypotenuse if the lengths of the legs are $3 \mathrm{~cm}$ and $4 \mathrm{~cm}$.

7. Change $2 \mathrm{~mm}$ into meters and decimeters

8. = Divide and reduce the fraction

\section{Publisher}

Federal University of Goiás. School of Music and Performing Arts. Graduate Program in Music. Publication in the Portal of Periodicals UFG.

The ideas expressed in this article are the responsibility of their authors, and do not necessarily represent the opinion of the editors or the university. 